\title{
Antiphospholipid antibodies enhance rat neonatal cardiomyocyte apoptosis in an in vitro hypoxia/reoxygenation injury model via p38 MAPK
}

\author{
Lauren T Bourke ${ }^{1,2}$, Thomas McDonnell ${ }^{1}$, James McCormick ${ }^{3}$, Charis Pericleous ${ }^{1}$, Vera M Ripoll ${ }^{1}$, lan Giles ${ }^{1}$, Anisur Rahman ${ }^{1}$, \\ Anastasis Stephanou ${ }^{4}$ and Yiannis loannou ${ }^{*, 1,2}$
}

A significant amount of myocardial damage during a myocardial infarction (MI) occurs during the reperfusion stage, termed ischaemia/reperfusion (I/R) injury, and accounts for up to $50 \%$ of total infarcted tissue post-Ml. During the reperfusion phase, a complex interplay of multiple pathways and mechanisms is activated, which ultimately leads to cell death, primarily through apoptosis. There is some evidence from a lupus mouse model that lupus IgG, specifically the antiphospholipid (aPL) antibody subset, is pathogenic in mesenteric $1 / R$ injury. Furthermore, it has previously been shown that the immunodominant epitope for the majority of circulating pathogenic aPLs resides in the N-terminal domain I (DI) of beta-2 glycoprotein I $\left(\beta_{2} \mathrm{GPI}\right.$ ). This study describes the enhanced pathogenic effect of purified IgG derived from patients with lupus and/or the antiphospholipid syndrome in a cardiomyocyte $H / R$ in vitro model. Furthermore, we have demonstrated a pathogenic role for aPL containing samples, mediated via aPL- $\beta_{2} \mathrm{GPI}$ interactions, resulting in activation of the pro-apoptotic p38 MAPK pathway. This was shown to be inhibited using a recombinant human peptide of domain I of $\beta_{2} \mathrm{GPI}$ in the fluid phase, suggesting that the pathogenic anti- $\beta_{2} \mathrm{GPI}$ antibodies in this in vitro model target this domain.

Cell Death and Disease (2017) 8, e2549; doi:10.1038/cddis.2016.235; published online 12 January 2017

The antiphospholipid syndrome (APS) is characterised by the clinical syndrome of arterial and venous thrombosis and/or recurrent pregnancy morbidity in association with the presence of antiphospholipid (aPL) antibodies. ${ }^{1}$ Beta-2 glycoprotein I ( $\left.\beta_{2} \mathrm{GPI}\right)$ consists of five homologous peptide subunits, which are termed domains $\mathrm{I}$ to $\mathrm{V}^{2,3}$ with domain $\mathrm{V}$ being responsible for binding anionic phospholipid. ${ }^{4}$ A subpopulation of aPL derived from patients with APS binds phospholipids via domain I of the protein co-factor $\beta_{2} \mathrm{GPI}$ to promote thrombosis, ${ }^{5,6}$ and these anti-DI antibodies have been proven to be pathogenic in an animal model of venous thrombosis. ${ }^{7,8}$

Myocardial infarction (MI) is an important cause of morbidity and mortality in systemic lupus erythematosus (SLE) and many patients with SLE also have co-existing APS. It is widely accepted that accelerated atherosclerosis is a key contributor to cardiovascular-related morbidity and mortality in lupus; however, the role of I/R injury is yet to be explored. APS is associated with a greater risk of atherosclerosis compared with matched controls ${ }^{9}$ and accounts for one in nine Mls. ${ }^{10}$ There is some evidence within a lupus mouse mesenteric I/R injury model that lupus IgG are pathogenic. ${ }^{11}$ Additionally $\mathrm{aPL}$, which are found in $30-40 \%$ of lupus patients, ${ }^{12}$ as well as those with only APS (primary APS) has been shown to specifically restore mesenteric $\mathrm{I} / \mathrm{R}$ injury in a complement deficient mouse model. ${ }^{13}$ Therefore, if relevant to the myocardium, one might expect that cardiac infarct size postMI would be larger in patients with SLE and/or APS. However, to our knowledge no large-scale study has been undertaken to compare cardiac infarct sizes between patients with SLE \pm APS and age- and gender-matched controls. Given that patients with SLE have greater cardiovascular risks and increased mortality due to cardiovascular events, ${ }^{14}$ it is relevant to investigate if, at the experimental level, IgG from SLE and/or APS enhance cardiac I/R injury.

During the reperfusion phase of $\mathrm{I} / \mathrm{R}$ injury, a complex interplay of multiple pathways and mechanisms is activated, which ultimately culminate in cell death primarily through apoptosis. In vivo rat studies have shown that the number of TUNEL (terminal deoxynucleotidyl transferase-mediated dUTP nick-end labelling)-positive cardiomyocytes in I/R injury can be reduced by treatment with a caspase inhibitor, ${ }^{15}$ resulting in a reduced infarct size indicating that apoptosis plays an important role in I/R-induced damage. The mitogenactivated protein kinase (MAPK) family, which consists of a series of serine-threonine kinases, is known to play a role in cell proliferation, differentiation and survival, but have also been shown to be heavily implicated in I/R injury in both a proand anti-apoptotic fashion. Specifically, in vivo animal studies

\footnotetext{
${ }^{1}$ Centre for Rheumatology, Division of Medicine University College London, Rayne Institute, London, UK; ${ }^{2}$ Arthritis Research UK Centre for Adolescent Rheumatology, University College London, London, UK; ${ }^{3}$ Biochemistry Research Group, Clinical and Molecular Genetics Unit, Institute of Child Health \& Great Ormond Street Hospital, University College London, London, UK and ${ }^{4}$ Medical and Molecular Biology Unit, University College London, London, UK

*Corresponding author: Y loannou, Arthritis Research UK Centre for Adolescent Rheumatology, University College London, Room 411, Rayne Building, London WC1E 6JF, UK. Tel: +44 2031082157; Fax: +44 2034479278; E-mail: y.ioannou@ucl.ac.uk

Abbreviations: MAPK, mitogen-activated protein kinase; MI, myocardial infarction; I/R, ishaemia/reperfusion; aPL, antiphospholipid; DI, domain I; $\mathrm{B}_{2} \mathrm{GPI}$, beta-2 glycoprotein I; APS, antiphospholipid syndrome; SLE, systemic lupus erythematosus; TUNEL, terminal deoxynucleotidyl transferase dUTP nick-end labelling; CL, cardiolipin; H/R, hypoxia/reoxygenation; HCs, healthy controls; VT, vascular thrombosis; PM, pregnancy morbidity

Received 10.1.16; revised 01.6.16; accepted 27.6.16; Edited by H-U Simon
} 
have shown that inhibition of p38 MAPK via SB203580 results in a reduction in myocardial damage ${ }^{16}$ and improved cardiac function. ${ }^{17}$ Inhibition of p38 MAPK also leads to a reduction in inflammatory cytokines such as tumour necrosis factor alpha (TNF-a), interleukin-1 (IL-1) and interleukin-8 (IL-8), therefore reducing the pro-inflammatory response which is known to contribute to cardiac I/R injury. ${ }^{18}$

In the presence of serum co-factors, such as $\beta_{2} \mathrm{GPI}$, pathogenic anti-PL binds negatively charged $\mathrm{PL}$ such as cardiolipin (CL). ${ }^{19}$ This has been shown to result in an aPLmediated activation of $\mathrm{p} 38 \mathrm{MAPK}$ and NF-KB pathways in cultured human endothelial cells ${ }^{20}$ and monocytes. ${ }^{21-23}$ One may hypothesise that if $\beta_{2} \mathrm{GPI}$-dependent aPL were to also activate p38 MAPK in cardiomyocytes, then this would enhance apoptosis in cardiac I/R injury.

Here, we describe a pathogenic role for $\mathrm{PPL}$ antibodies in an in vitro model of cardiomyocyte hypoxia/reoxygenation $(\mathrm{H} / \mathrm{R})$ injury. This injury is shown to be induced via the pro-apoptotic p38 MAPK. Furthermore, in the absence of $\beta_{2} \mathrm{GPI}$ or the presence of a recombinant human DI decoy peptide pathogenicity was abrogated, suggesting this effect is mediated through antibodies targeting DI of $\beta_{2} \mathrm{GPI}$.

\section{Results}

Clinical and laboratory characteristics of individuals. A total of 11 patients with APS, 9 SLE/aPL negative (APS negative) and 15 healthy controls (HCs) subjects were studied (Table 1). Of the 35 subjects, 28 were female. Of 11 patients with APS, 5 had SLE (clinical and serological details are shown in Table 1) and 6 primary APS.

IgG purified from patients with SLE enhances apoptosis in neonatal rat cardiomyocytes within an in vitro $H / R$ injury model. An in vitro simulated model of cardiac $H / R$ injury was used, whereby neonatal rat cardiomyocytes were isolated and pre-treated with $500 \mu \mathrm{g} / \mathrm{ml} \mathrm{IgG} \mathrm{purified} \mathrm{from}$ patients with SLE and $\mathrm{HC}$, and then exposed to $\mathrm{H} / \mathrm{R}$ injury. Pre-incubation with $\mathrm{HC}$ IgG resulted in an increase of $7.3 \%$ $( \pm$ S.D. 3.9, $n=5)$ in TUNEL-positive cells compared with untreated cells exposed to $H / R$ injury (Figure 1). However, when cells were pre-incubated with IgG purified from patients with SLE, TUNEL positivity was significantly enhanced further to $54.2 \%$ ( \pm S.D. 8.1, $n=6, P=0.0043$ ).
To assess if this pro-apoptotic role for SLE autoantibodies in this in vitro $\mathrm{H} / \mathrm{R}$ was dependent on the presence of APSrelated autoantibodies, further experiments were performed using another marker of apoptosis, cleaved caspase-3 and an expanded set of patient IgG samples allowing groups to be compared between those that are SLE/APS positive versus SLE/APS negative and APS alone. Figure 2 shows effects on cleaved caspase-3 upon incubation with IgG from the different subject groups. SLE-derived IgG had a pro-apoptotic effect in this model but the presence of APS-derived IgG had a significantly greater pro-apoptotic effect over and above that seen in SLE/APS-negative IgG. Compared with untreated cells, HC IgG treatment did not alter cleaved caspase-3 levels whereas these levels were significantly increased by $68.15 \%$ ( \pm S.D. $13.5, n=5, P<0.0005$ ) in the presence of SLE/APS IgG and by $67.94 \%( \pm$ S.D. $12.41, n=6, P<0.0005)$ in the presence of primary APS IgG but by only $40.66 \%$ ( \pm S.D. 8.7 , $n=5, P<0.0005)$ in the presence of SLE/APS-negative IgG. Thus, since the two APS groups gave very similar results we chose to combine them in subsequent experiments reported in this paper, which all compare three groups: APS, SLE/APS negative and $\mathrm{HC}$.

The pathogenic effect of APS IgG is dependent upon enhanced phosphorylation of the pro-apoptotic MAPK p38 in neonatal rat cardiomyocytes within an in vitro H/R injury model. Enhancement of MAPK p38 phosphorylation was observed in the presence of APS IgG but not SLE/APSnegative IgG when compared with cells treated with $\mathrm{HC} \operatorname{lgG}$ during $H / R$ injury (Figure $3 a$ ). The mean ratio of phosphorylated to total p38 MAPK was 0.52 ( \pm S.D. 0.37) in cells treated with APS IgG versus $0.12( \pm$ S.D. 0.12$)$ in cells treated with SLE/APS-negative IgG $(P=0.0174)$. However, APS IgG did not significantly affect levels of Akt and ERK 1/2 phosphorylation (Figures $3 \mathrm{~b}$ and $\mathrm{c}$ ). It should be noted that the p44 isoform of ERK 1/2 had reduced phosphorylation in the presence of APS IgG when compared with SLE/APSnegative IgG, although this was not significantly different.

Co-incubation with a p38 MAPK-specific inhibitor (SB23580) reduced the effect of APS IgG on levels of cleaved caspase-3 (Figure 4). Thus, cleaved caspase-3 levels relative to GAPDH was 0.81 ( \pm S.D. 0.17 ) in the presence of APS IgG, but $0.40( \pm$ S.D. 0.14$)$ in the presence of APS IgG plus SB23580 $(P=0.029)$. In fact, presence of this inhibitor reduced cleaved caspase-3 almost to the levels seen with

Table 1 Clinical characteristics and binding properties of patient cohort

\begin{tabular}{|c|c|c|c|c|}
\hline & Primary APS $(n=6)$ & SLE/aPL +ve $(n=5)$ & $\begin{array}{c}\text { SLE/aPL -ve } \\
(n=9)\end{array}$ & $\begin{array}{l}\text { Healthy controls } \\
\qquad(n=15)\end{array}$ \\
\hline $\begin{array}{l}\text { Age (mean } \pm \text { SEM) } \\
\text { Sex } \\
\text { Serum aCL (mean GPLU } \pm \text { SEM) } \\
\text { Serum anti- } \beta_{2} \text { GPI (mean } \mathrm{SU}_{ \pm} \text {SEM) } \\
\text { Serum anti-DI (mean as a \% binding to an in- } \\
\text { house standard) }\end{array}$ & $\begin{array}{c}55( \pm 4.5) \\
3 \mathrm{~F} / 3 \mathrm{M} \\
50.0( \pm 20.65) \\
91.6( \pm 19.7) \\
35.56( \pm 38.96)\end{array}$ & $\begin{array}{l}45.2( \pm 5.1) \\
\quad 5 \mathrm{~F} \\
43.26( \pm 15.83) \\
49.62( \pm 16.1) \\
11.85( \pm 3.98)\end{array}$ & $\begin{array}{l}42.8( \pm 6.3) \\
\quad 8 \mathrm{~F} \\
3.62( \pm 0.34) \\
3.58( \pm 0.3) \\
4.20( \pm 2.57)\end{array}$ & $\begin{array}{l}35.2( \pm 4.7) \\
8 \mathrm{~F} / 2 \mathrm{M} \\
4.12( \pm 0.58) \\
5.4( \pm 0.7) \\
3.56( \pm 1.78)\end{array}$ \\
\hline
\end{tabular}

Patients with APS $(n=11)$ are separated into clinical groups (primary APS and SLE/APS positive). The mean age ( + S.D.) of each patient subgroup and for the HC group is also shown. Purified polyclonal IgG was tested in aCL, anti- $\beta_{2} \mathrm{GPI}$ and anti-DI (of $\beta_{2} \mathrm{GPI}$ ) direct binding assays and mean values (from duplicate experiments \pm S.D.) are shown here. For aCL, mean activity is shown in GPLU, anti- $\beta_{2}$ GPI is shown in GDU (IgG arbitrary units) and anti-DI as the percentage activity of an in-house standard 

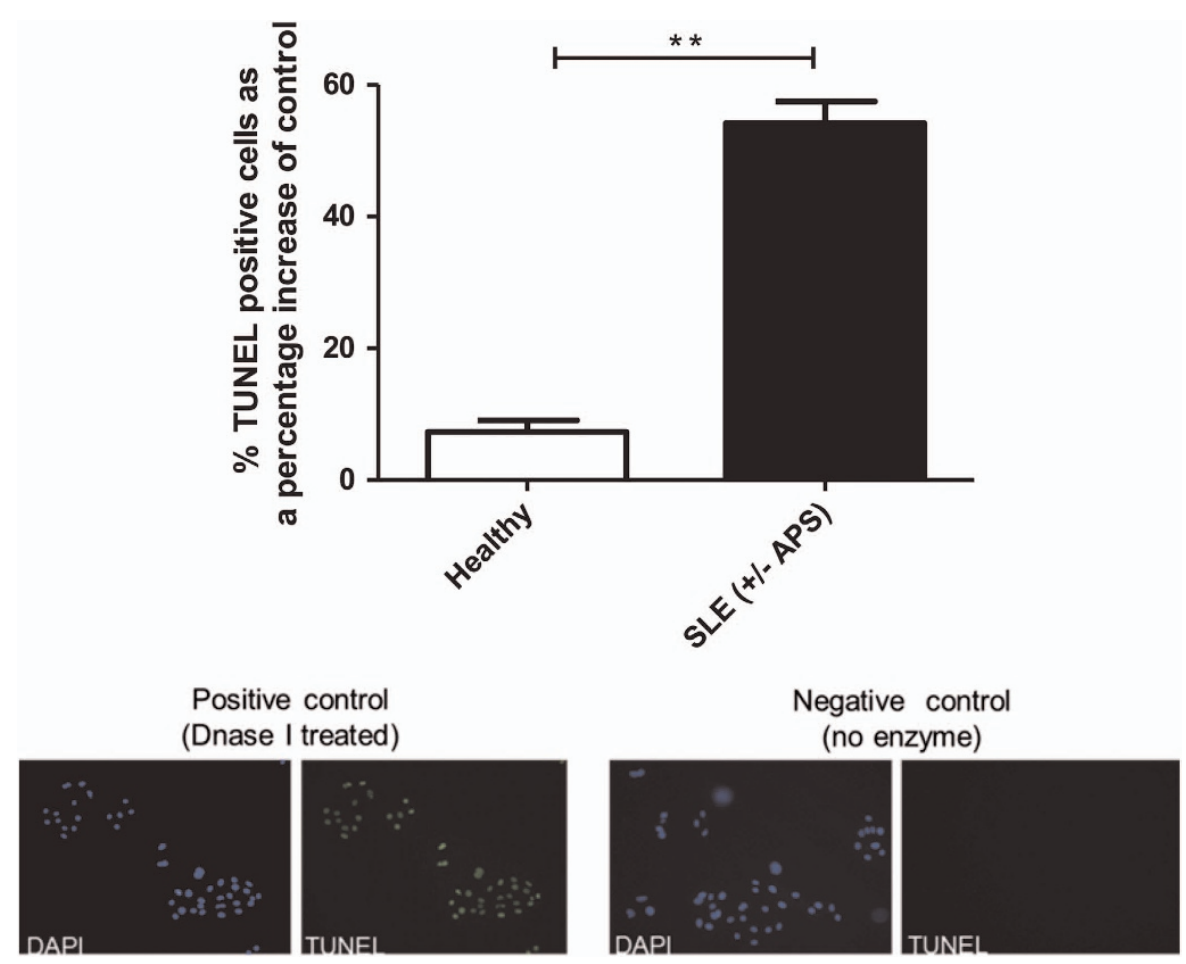

Figure $1 \mathrm{lgG}$ from patients with SLE enhances the number of TUNEL-positive cells in neonatal rat cardiomyocytes exposed to H/R injury. Neonatal rat cardiomyocytes were pre-treated with $500 \mu \mathrm{g} / \mathrm{ml} \mathrm{lgG}$ from either healthy or SLE patients and the following day cells were exposed to H/R injury (4 h hypoxia+16 h reoxygenation). Cells were fixed in $4 \%$ PFA and the percentage of TUNEL-positive cells was assessed. Graph shows mean \pm S.E.M. of quantitative analysis from six SLE patients and five healthy controls. Statistical analysis was determined by Mann-Whitney $U$-test $\left({ }^{* *} P=0.0043\right)$

SLE/APS-negative IgG $-0.29( \pm$ S.D. 0.12$)$ but not to levels seen with $\mathrm{HC} \operatorname{IgG}-0.12( \pm$ S.D. 0.1). No significant effect on cleaved caspase-3 level was observed with the p38 inhibitor in cells that were untreated, or treated with HC IgG or SLE/APSnegative IgG.

Removal of $\beta_{2}$ GPI from serum abrogates the pathogenic effect of APS-positive IgG in neonatal rat cardiomyocytes within an in vitro $\mathbf{H} / \mathbf{R}$ injury model. The depletion of $\beta_{2} \mathrm{GPI}$ from human serum led to loss of the pathogenic effect of APS IgG on cleaved caspase-3 levels when exposed to H/R injury. When cells cultured in $\beta_{2} \mathrm{GPI}$-deficient serum were spiked with human $\beta_{2} \mathrm{GPI}$, the pathogenic effect of APS-positive IgG was restored (Figure 5a).

A recombinant human DI decoy peptide blocks the pathogenic effect of APS-positive IgG in neonatal rat cardiomyocytes within an in vitro $H / R$ injury model. Purified IgG was pre-incubated with recombinant DI for $2 \mathrm{~h}$ prior to incubation with cells. In the presence of the DI peptide the effect of APS IgG on cleaved caspase-3 was inhibited (Figure $5 b$ ). In cells treated with APS IgG and exposed to H/R injury, the addition of DI peptide led to a $48.81 \%( \pm$ S.D. 34.07) inhibition in cleaved caspase-3 level. Addition of DI caused much smaller reductions in levels of cleaved caspase-3 in cells treated with $\mathrm{HC}$ IgG (reduction $3.14 \%( \pm$ S.D. 7.9) $-P=0.0045$ compared with APS IgG) or SLE/APSnegative IgG (reduction 6.2\% ( \pm S.D. 10.84) $-P=0.0145$ compared with APS IgG).
In addition, the ability of the recombinant DI to inhibit binding of IgG from the APS patient cohort to solid-phase $\beta_{2}$ GPI was measured by ELISA. Importantly, serum from all nine patients had demonstrated high activity in our in-house solid-phase $\beta_{2}$ GPI ELISA assay. The ability of recombinant DI at concentrations ranging from 0 to $80 \mu \mathrm{g} / \mathrm{ml}$ to inhibit binding of all nine sera to solid-phase $\beta_{2} \mathrm{GPI}$ in this assay was then tested. Figure $5 \mathrm{c}$ shows that six serum samples were inhibited by the presence of the DI peptide to different degrees. Figure $5 \mathrm{~d}$ compares the reduction in cleaved caspase-3 caused by DI in cultured cardiomyocytes exposed to APS IgG samples from individual patients with the percentage by which binding to $\beta_{2}$ GPI of the same APS IgG samples is inhibited by $D \mathrm{l}$ at the same concentration $(40 \mu \mathrm{g} / \mathrm{ml})$. There was a positive correlation between these two separate measures of $\mathrm{DI}$ inhibition of these samples $(r=0.6775, P=0.0459)$.

\section{Discussion}

A novel pathogenic role for aPL autoantibodies has been identified by demonstrating a pro-apoptotic effect within an in vitro model of cardiomyocyte $\mathrm{H} / \mathrm{R}$ injury. Furthermore, the mechanism through which this pathogenic effect may be mediated has been dissected using a range of time points to fully understand this complex interplay of signalling pathways. Fleming et al. ${ }^{13}$ have previously shown that in a mesenteric l/R injury model that anti- $\beta_{2} \mathrm{GPI}$ autoantibodies restore local and remote tissue damage in a Complement Receptor 2/Complement Receptor 1-Deficient mouse model that is typically 


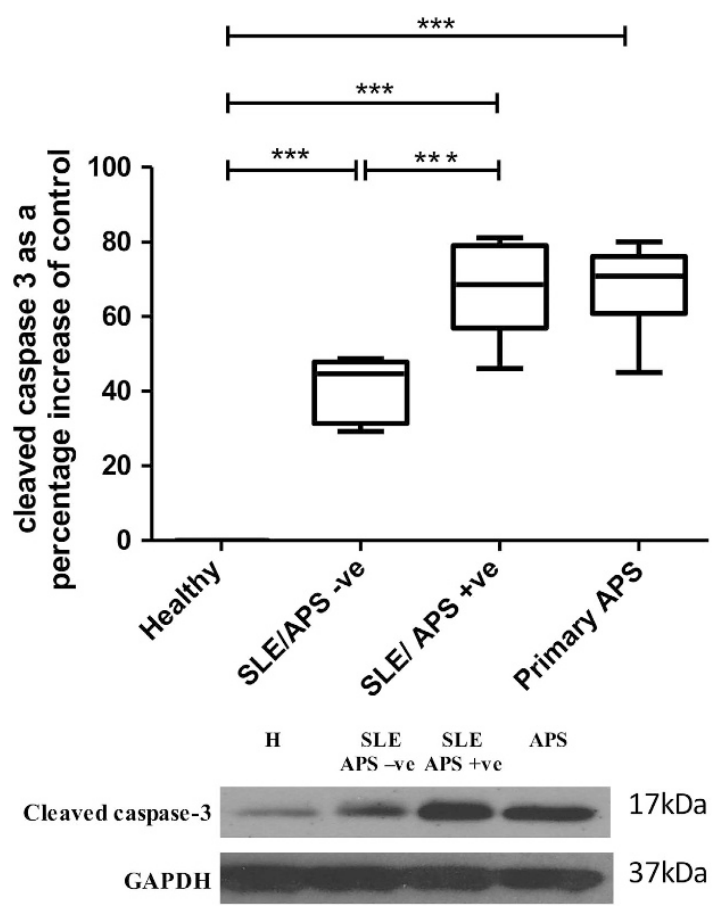

Figure 2 lgG from patients with SLE/APS +ve, SLE/APS -ve and APS enhances cleaved caspase-3 in neonatal rat cardiomyocytes in H/R injury. Cells were pretreated with $500 \mu \mathrm{g} / \mathrm{ml}$ healthy, SLE/APS negative, SLE/APS positive or primary APS $\lg G$. The following day cells were exposed to $H / R$ injury $(4 \mathrm{~h}$ hypoxia $+4 \mathrm{~h}$ reoxygenation) and the level of cleaved caspase-3 was assessed by western blot. Graph shows \pm S.E.M. of quantitative analysis from five SLE/APS-positive patients, five SLE/APS-negative patients, six primary APS patients and ten healthy controls. Graphical representations of the density ratios of each protein and GAPDH expressed as a percentage of untreated cells are displayed. Statistical analysis determined by one-way ANOVA using post hoc tukey to compare all columns $\left({ }^{\star * *} P<0.0005\right)$

protected from I/R injury. Owing to previous studies showing that $\mathrm{I} / \mathrm{R}$ injury mechanisms are similar in a variety of tissue types $^{13}$ and patients with APS having a greater risk of myocardial infarction, ${ }^{24}$ one may hypothesise that aPL antibodies play a pathogenic role also in the setting of the myocardium. This study has found that IgG purified from patients with SLE and/or APS enhanced apoptosis, as measured by an increase in TUNEL positivity (Figure 1). Levels of cleaved caspase-3 were also assessed in a larger cohort of patients and this pathogenic effect was confirmed (Figure 2). Moreover, enhanced cleaved caspase-3 was most pronounced in those patients who were APS positive (SLE/ aPL positive and primary APS), suggesting an aPL-dependent mechanism of pathogenicity distinct from patients with SLE.

Experiments were performed to identify potential mechanisms through which IgG from patients with APS caused pathogenicity in this H/R injury model. We found that APS IgG enhanced p38 MAPK phosphorylation significantly more than SLE/APS negative or HC IgG and that a p38 MAPK inhibitor (SB203580) reduced the increase in cleaved caspase-3 caused by APS IgG (Figure 4) This suggests that the enhanced pro-apoptotic effect of APS IgG is due to increased phosphorylation of the kinase p38 MAPK. The use of p38 MAPK inhibitors in the treatment of cardiac $I / R$ injury is currently being explored in a number of trials. ${ }^{25}$ In untreated cells, while p38 MAPK is enhanced by H/R injury, levels observed are low compared with APS IgG-treated cells. It could therefore be suggested that the p38 MAPK contribution to $H / R$ injury in the presence of a p38 MAPK stimulus such as APS IgG is greater and therefore an inhibitor would be more effective in reducing the pathogenic effects mediated by p38 MAPK in patients with APS.

It is acknowledged that in APS the dominant population of pathogenic autoantibodies target the circulating autoantigen $\beta_{2}$ GPI. ${ }^{26-29}$ To demonstrate if this APS IgG-mediated pathogenicity of cardiomyocyte $\mathrm{H} / \mathrm{R}$ injury was mediated through $\beta_{2} \mathrm{GPI}$ autoantibodies, cells were cultured in media containing $\beta_{2} \mathrm{GPI}$-deficient human serum in the presence of IgG from the different groups studied. It was observed that in the absence of this serum co-factor, there was a reduction in cleaved caspase-3 in the presence of APS IgG (Figure 5a), but when human $\beta_{2}$ GPI was added back into the system to a final concentration typically observed in humans, levels of cleaved caspase-3 were enhanced back to levels similar to that seen previously. This result did not reach statistical significance, with a noted limitation of this experiment being that pooled IgG was used, therefore potentially dampening the response observed by specific patient samples.

Although SLE/APS-negative IgG samples did have an effect on cleaved caspase-3 it was smaller than that of APS IgG. Also SLE/APS-negative IgG had no effect on MAPK p38 phosphorylation. This suggests an alternative mechanism of pathogenicity for this polyclonal population of IgG. Many different autoantibody specificities have been identified in SLE. Anti-Ro antibodies can affect the fetal heart causing neonatal lupus play and could also have effects in adults; ${ }^{30}$ however, clinical data confirm that the majority of our patients are anti-Ro negative. It is possible that a yet to be identified population of antibodies may be pathogenic in this model of cardiomyocyte H/R injury. Further studies are now required to try and identify both the autoantibody populations and the epitopes to which they bind to cause a pathogenic effect.

Studies using domain deletion mutants of $\beta_{2} \mathrm{GPI}$, in which one or more domains are missing, have shown that the immunodominant epitope which binds the pathogenic anti$\beta_{2}$ GPI APS autoantibodies is located in $\mathrm{DI}^{5,6}$ and recombinant $\mathrm{DI}$ can bind these APS autoantibodies in both the solid and fluid phase. ${ }^{31,32}$ Pre-incubating APS-positive IgG from individual patients with recombinant human DI, prior to treatment of cells, reduced cleaved caspase-3 in H/R injury (Figure $5 b$ ). This suggests that DI inhibits the pathogenic effect of APSpositive IgG through a decoy mechanism, in which it binds the APS during the pre-incubation stage, therefore causing a protective effect. Additionally, the serum from the APS-positive IgG samples selected were tested in a competition based ELISA, to see if fluid-phase recombinant DI could inhibit IgG from binding to solid-phase $\beta_{2} \mathrm{GPI}$. It was observed that increasing $\mathrm{DI}$ concentrations reduced binding (Figure $5 \mathrm{c}$ ), which correlated with reductions in cleaved caspase-3 (Figure $5 d$ ), further supporting the case that it is anti-DI antibodies that are the dominant pathogenic population in this in vitro $\mathrm{H} / \mathrm{R}$ cardiac injury simulation model. However, to definitively prove that anti-DI are the pathogenic 
a
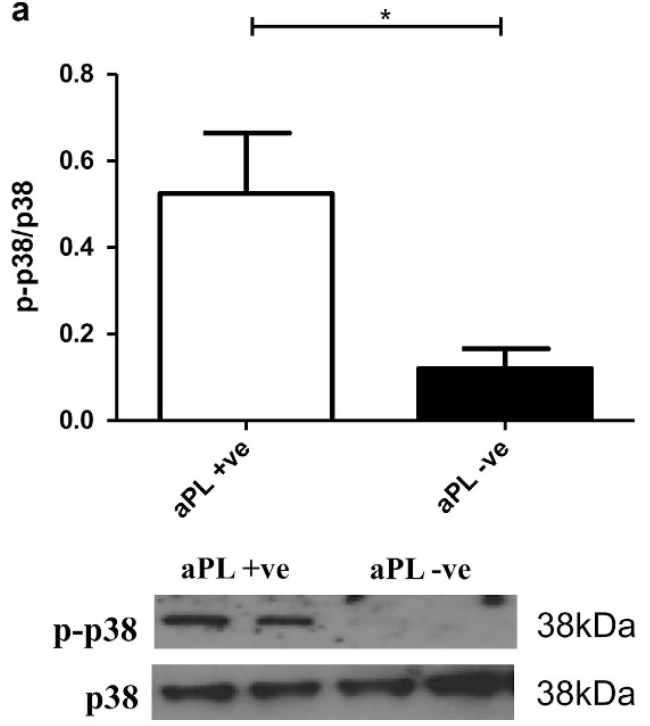

C

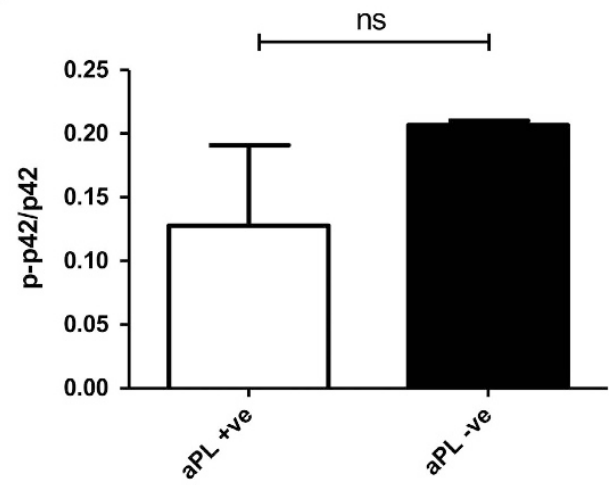

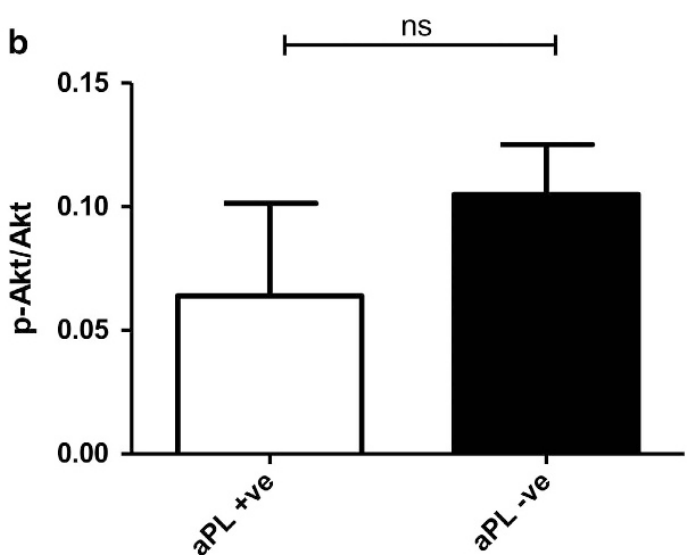

aPL +ve aPL -ve

p-Akt

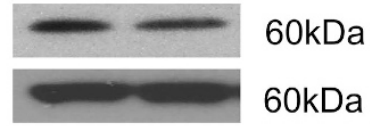

Akt
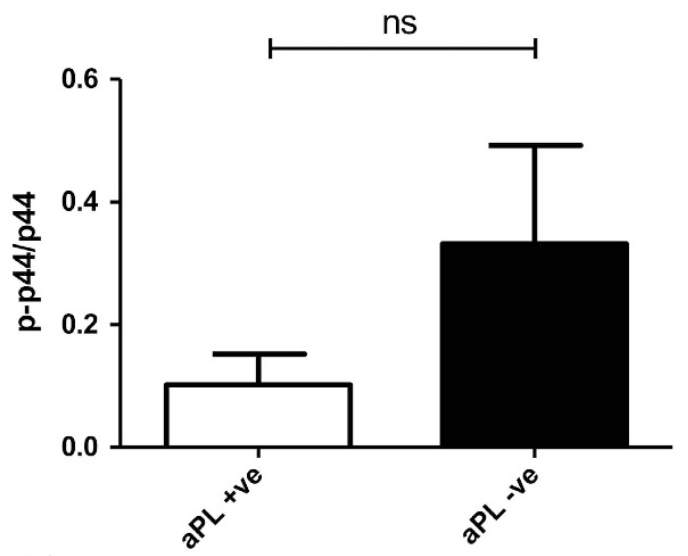

$42 / 44 \mathrm{kDa}$

$42 / 44 \mathrm{kDa}$

Figure $3 \mathrm{IgG}$ purified from APS patients increases the pro-apoptotic kinase p38 MAPK phosphorylation in neonatal rat cardiomyocytes in $\mathrm{H} / \mathrm{R}$ injury. Cells were pre-treated with $500 \mu \mathrm{g} / \mathrm{ml} \mathrm{lgG}$ (APS (primary or SLE/APS) and SLE/APS negative). The following day cells were exposed to H/R injury ( $4 \mathrm{~h} \mathrm{hypoxia}+4 \mathrm{~h}$ reoxygenation) and the levels of p38 MAPK (a), Akt (b) and ERK 1/2 (p42/p44) (c) phosphorylation assessed using western blot. Graphical representations of the density ratios of each phosphorylated to total protein expressed in arbitrary scanning units are displayed. Graph shows \pm S.E.M. of quantitative analysis from five independent experiments. Statistical analysis determined by unpaired $t$-test $\left({ }^{*} P=0.0179\right)$

subpopulation of aPL that enhance cardiomyocyte H/R injury, these antibodies must be affinity purified from multiple patients and then tested in an in vivo cardiac $H / R$ model, ideally compared with affinity purified anti- $\beta_{2} \mathrm{GPI}$ antibodies binding to domains other than DI. The results presented in this article underpin these detailed future in vivo studies.

The next question to be answered is what cell surface receptors $\beta_{2} \mathrm{GPI}$ is binding to, to induce this response. It has previously been shown that $\beta_{2} \mathrm{GPI}$ has the ability to bind to a range of receptors including TLR4, TLR2, Annexin A2 and Ro $60 .^{33-36}$ A known downstream activator of TLR4 is p38 $\mathrm{MAPK}^{22}$ and therefore it could be suggested that the APS autoantibodies are mediating their pathogenic effect via this receptor. Additionally, TLR4 has been implicated in I/R injury, with TLR4-deficient mice showing cardioprotection in an in vivo I/R injury model. ${ }^{37,38}$ Further experiments are now required to confirm this.

In humans, there is no large-scale study to our knowledge that has compared cardiac infarct sizes between patients with APS \pm SLE and age- and gender-matched controls. This in vitro study provides the first evidence that autoantibodies, a prominent feature of patients with $\mathrm{APS} \pm \mathrm{SLE}$, may play a role in the degree of damage to the myocardium in I/R injury and propose a novel non-thrombotic role for these autoantibodies 

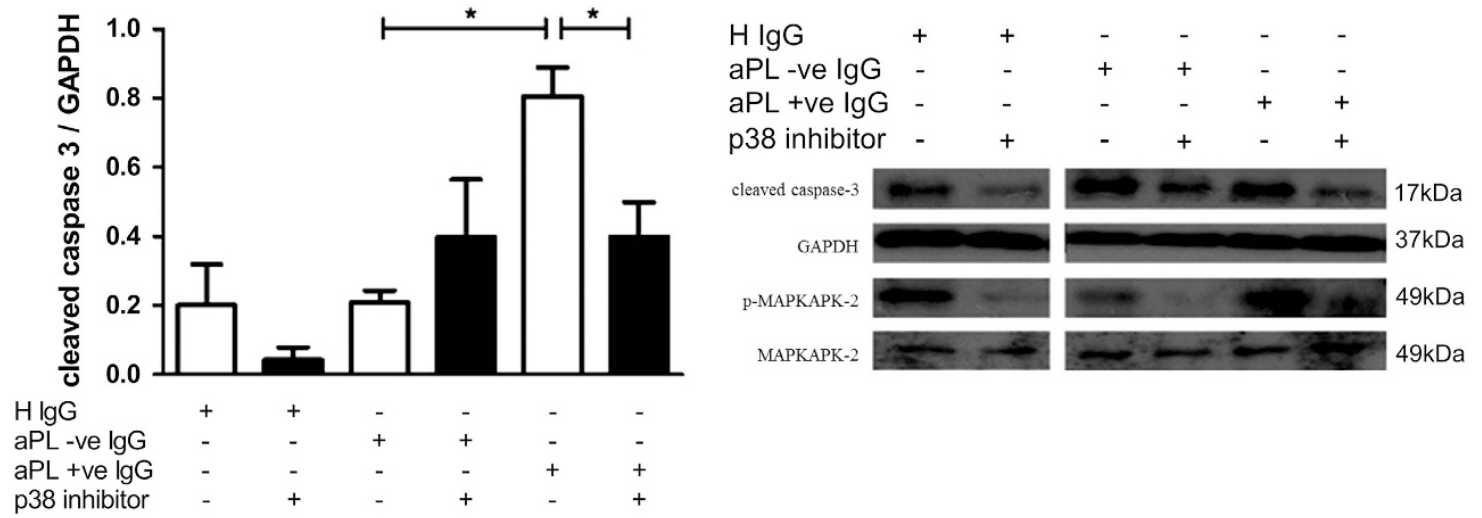

Figure 4 The p38 inhibitor SB23580 prevents IgG from APS patients enhancing cleaved caspase-3 in neonatal rat cardiomyocytes in H/R injury. Cells were pre-treated with $10 \mu \mathrm{M}$ SB203580 and $2 \mathrm{~h}$ later $500 \mu \mathrm{g} / \mathrm{ml} \mathrm{lgG}$ (healthy, APS positive (primary and SLE/APS) and SLE/APS negative). The following day cells were exposed to H/R injury (4 $\mathrm{h}$ hypoxia $+2 \mathrm{~h}$ reoxygenation) and the levels of cleaved caspase-3 and phosphorylated MAP kinase-activated protein kinase 2 (p-MAPKAPK2) were assessed using western blot. Graph shows \pm S.E.M. of quantitative analysis from four independent experiments. Graphical representations of the density ratios of each protein and GAPDH expressed in arbitrary scanning units are displayed. Statistical analysis determined by unpaired $t$-test ( ${ }^{*} P=0.0256,{ }^{*} P=0.0286$ )

in this organ. Further studies using affinity purified anti-DI antibodies within a passive transfer animal model of cardiac $\mathrm{I} / \mathrm{R}$ injury to confirm pathogenicity in vivo are now required. The outcome of this research may identify a new mechanism through which antibodies from patients with APS \pm SLE may cause cardiac damage following an Ml. This research could then underpin future clinical studies to determine if patients with $\mathrm{APS} \pm$ SLE are susceptible to a larger $\mathrm{Ml}$ and/or stroke as compared with age- and gender-matched controls. Ultimately, this may lead to identification of novel pathogenic roles for antibodies from patients with $\mathrm{APS} \pm$ SLE and investigation of potential new targets and therapeutics with the aim of ultimately improving outcomes for patients with these conditions and cardiovascular disease.

\begin{abstract}
Materials and Methods
Patients. Serum samples were obtained from 35 individuals for this study with informed consent and local ethical approval in accordance with the Declaration of Helsinki. We studied three groups of subjects. The first group of 11 patients had APS; 5 with SLE-associated APS (1 vascular thrombosis (VT) and pregnancy morbidity (PM) and 4 VT) and 6 with primary APS (1 PM and 5 VT). The second group of nine patients had SLE but no serum aPL and no clinical features of APS. The third group were 15 healthy controls $(\mathrm{HCs})$ who also had no serum aPL. All patients with APS and SLE fulfilled the current accepted classification criteria. ${ }^{39,40}$
\end{abstract}

Immunological characterisation and purification of IgG. IgG was protein $G$ purified, passed through endotoxin removal columns (Pierce, ThermoFisher, Basingstoke, UK), and confirmed to be $<0.06$ endotoxin units per millilitre by Limulus ameboycte lysate assay (Sigma-Aldrich, St. Louis, MO, USA) as described previously. ${ }^{41}$ Total $\lg G$ concentration was determined by spectrophotometry. Serum and IgG aCL, anti- $\beta_{2} \mathrm{GPI}$ and anti-DI titres were determined by enzyme-linked immunosorbent assay (ELISA) as described previously. ${ }^{31}$ Serum levels are reported in Table 1, activity levels were re-confirmed after IgG purification and activity was retained (data not shown).

Expression and purification of recombinant DI. Expression of wildtype recombinant human DI in Escherichia coli and purification using cytoplasmic inclusion bodies from which $\mathrm{DI}$ can be re-folded was performed as described previously. ${ }^{42}$ Subsequent cleavage with factor Xa removed the hexahistidine tag, resulting in native DI peptide.
Competitive inhibition assay. A competitive inhibition ELISA was used to assess the ability of recombinant DI in the fluid phase to inhibit binding of aPL to solid phase whole $\beta_{2} \mathrm{GPI}$. Prior to the assay, our in-house standard $\beta_{2} \mathrm{GPI}$ ELISA previously described ${ }^{32}$ was used to assess at what dilution of serum corresponded to $50 \%$ of the maximal binding absorbance unit of the serum. This ELISA was then repeated with the following amendment - anti- $\beta_{2} \mathrm{GPI}$ inhibition curves were constructed by pre-incubating sera from patients with APS with varying concentrations of recombinant $\mathrm{DI}$ (ranging from 0 to $80 \mu \mathrm{g} / \mathrm{ml}$ ) for $2 \mathrm{~h}$ at room temperature prior to addition to a 96 -well plate.

Primary neonatal rat ventricular cardiomyocyte isolation. Primary cardiomyocytes were isolated as previously described. ${ }^{43}$ All animal studies were approved by the University College London Biological Services Ethical Review Committee and licensed under the UK Home Office regulations and the Guidance for the Operation of Animals (Scientific Procedures) Act 1986 (Home Office, London, UK). All isolation buffers were oxygenated by bubbling medical grade oxygen through the solution for 5 min prior to use. Neonate rat pups (SpragueDawley) that were <2day postpartum were decapitated and rinsed in ethanol. The hearts were removed by cutting along the sternum and dissecting the heart through the chest wall. Hearts were washed in isolation buffer $(116 \mathrm{mM} \mathrm{NaCl}, 20 \mathrm{mM}$ HEPES, $0.77 \mathrm{mM} \mathrm{NaH}{ }_{2} \mathrm{PO}, 5.5 \mathrm{mM}$ glucose, $5.4 \mathrm{mM} \mathrm{KCl}, 0.4 \mathrm{mM} \mathrm{MgSO}$ containing $600 \mu \mathrm{g} / \mathrm{ml}$ collagenase type II and $250 \mu \mathrm{g} / \mathrm{ml}$ pancreatin) and cut into small $2 \mathrm{~mm}$ pieces and then incubated at $37^{\circ} \mathrm{C}$ until plating. The digestion procedure was repeated seven times and the pellets pooled and pre-plated for $1 \mathrm{~h}$ in $15 \%(\mathrm{v} / \mathrm{v})$ fetal bovine serum (FBS) in DMEM to remove contaminating fibroblasts. Cardiomyocytes were then seeded at $2 \times 10^{6}$ cells per well of a six-well plate, which had been pre-coated with $1 \%$ (w/v) gelatin (Sigma-Aldrich). The DMEM containing 15\% (v/v) FBS was replaced the following day with maintenance media (DMEM containing 1\% (v/v) FBS) or 1\% Human Apo H Deficient Serum (Assay Pro). For lgG incubations cells were pre-treated with $500 \mu \mathrm{g} / \mathrm{ml}$ purified polyclonal IgG from patient or healthy control serum overnight prior to $H / R$ injury. For $D I$ peptide experiments, IgG was pre-incubated with $40 \mu \mathrm{g}$ recombinant DI peptide for $2 \mathrm{~h}$ at room temperature, prior to incubation with cells. A control experiment was performed, whereby cells were incubated with bovine serum albumin (BSA) at $500 \mu \mathrm{g} / \mathrm{ml}$ to confirm that the effect observed was IgG specific. No difference in cleaved caspase- 3 was observed when compared with untreated cells (data not shown).

In vitro $\mathrm{H} / \mathrm{R}$ injury. Cell culture media was replaced with ischaemic buffer $\left(137 \mathrm{mM} \mathrm{NaCl}, 12 \mathrm{mM} \mathrm{KCl}, 0.49 \mathrm{mM} \mathrm{MgCl}, 0.9 \mathrm{mM} \mathrm{CaCl} \mathrm{H}_{2} \mathrm{O}, 4 \mathrm{mM}\right.$ HEPES, $20 \mathrm{mM}$ sodium lactate and $10 \mathrm{mM}$ deoxyglucose (pH 6.2)) and cells transferred to an in-house built anoxic chamber pre-warmed to $37^{\circ} \mathrm{C}$. Simulated ischaemia was achieved by addition of $5 \% \mathrm{CO}_{2}$ in balanced argon to exclude any oxygen. 
a

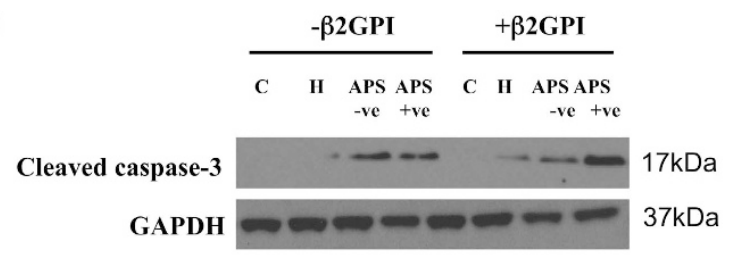

b

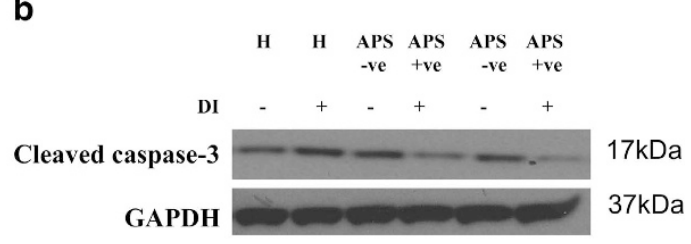

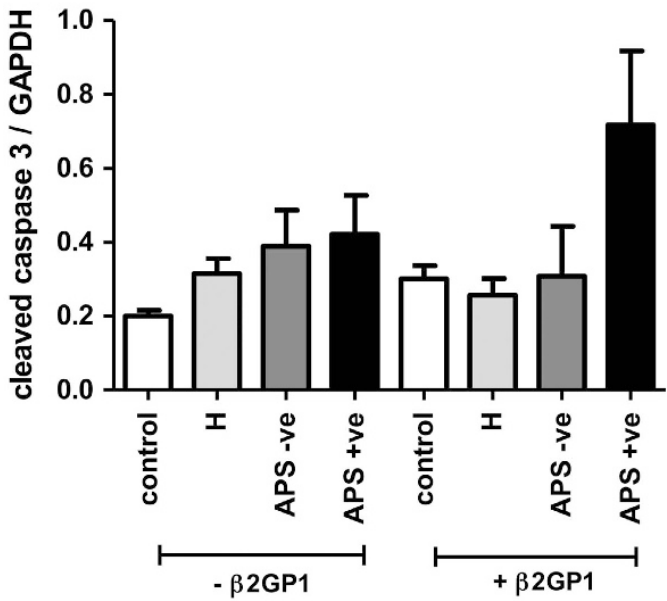

C

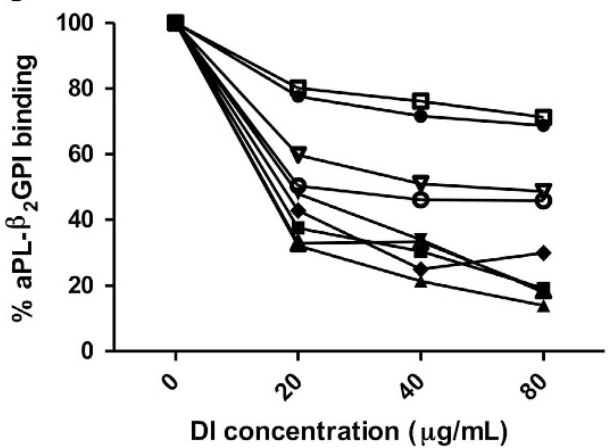

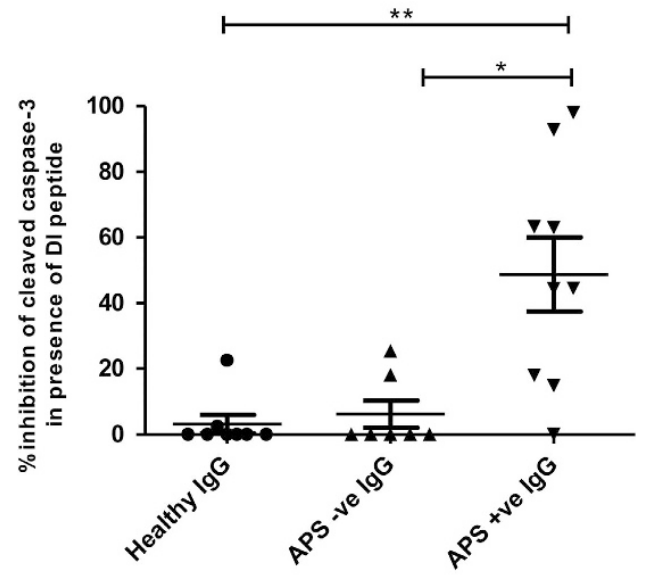

d

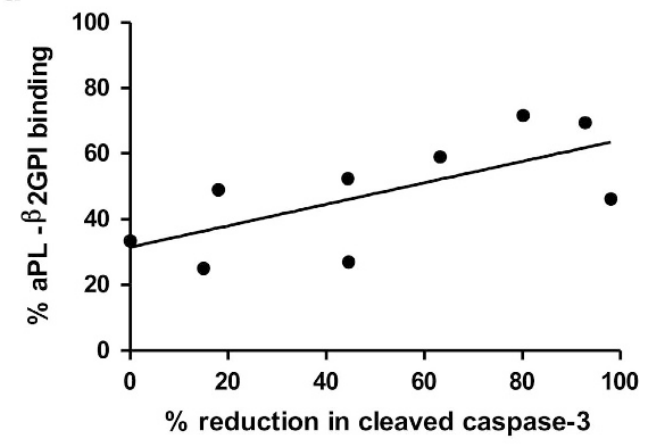

Figure 5 The pathogenic effect of APS-positive IgG is reduced in the presence of fluid-phase DI peptide. Neonatal rat cardiomyocytes were cultured in human $\beta_{2} \mathrm{GPI}$ deficient serum $\left(+/-\right.$ spiked human $\beta_{2} \mathrm{GPI}$ at a final concentration of $\left.200 \mu \mathrm{g} / \mathrm{ml}\right)$ and pre-treated overnight with $500 \mu \mathrm{g} / \mathrm{ml} \mathrm{lgG}$ (pooled from 5 patients per group) (a). IgG purified from APS positive (primary APS or SLE/APS) $(n=9)$ SLE/APS negative $(n=7)$ or healthy controls $(n=8)$ were pre-incubated for $2 \mathrm{~h}$ at room temperature with $40 \mu \mathrm{g}$ of recombinant DI peptide or PBS. Cells were then treated with IgG+PBS/lgG+Dl overnight (b). The following day cells were exposed to $\mathrm{H} / \mathrm{R}$ injury $(4 \mathrm{~h} \mathrm{hypoxia}+2 \mathrm{~h}$ reoxygenation) and levels of cleaved caspase- 3 were assessed using western blot $(\mathbf{a}+\mathbf{b})$. A competition based ELISA was performed to measure the ability of DI to bind to IgG from the APSpositive group $(n=9)$ (c). The percentage aPL- $\beta_{2}$ GPI binding at $40 \mu \mathrm{g}$ of DI peptide correlated with percentage reduction in cleaved caspase-3 for the APS positive (primary APS and SLE/APS positive) samples $(r=0.6755, P=0.0459)(n=9)(\mathbf{d})$. Graphical representations of the density ratios of each protein and GAPDH expressed as a percentage of increase of $\lg \mathrm{G}+\mathrm{DI}$ compared with $\lg \mathrm{G}+\mathrm{PBS}$ are displayed. Statistical analysis determined by Mann-Whitney U-test $(\mathbf{a})\left({ }^{*} P=0.0145,{ }^{* *} P=0.0045\right)$

Cells were subjected to simulated ischaemic injury for $4 \mathrm{~h}$ after which ischaemic buffer was replaced with DMEM containing $1 \%(\mathrm{~V} / \mathrm{V}) \mathrm{FBS}$ and cultured in $5 \% \mathrm{CO}_{2}$ in air (simulated reperfusion) for the indicated times. Optimisation of $H / R$ injury was performed using TUNEL (Supplementary Figure S1).

Determination of apoptosis. Cells were seeded on UV-irradiated coverslips and fixed in $4 \%(\mathrm{w} / \mathrm{V})$ paraformaldehyde in phosphate-buffered saline (PBS) for $15 \mathrm{~min}$ at room temperature. In situ cell death was detected in cultured cardiomyocytes by using TUNEL assay kit (Roche Diagnostics, Meylan, France) according to the manufacturer's instructions. Cells were then washed and cell nuclei counter stained with DAPI. Coverslips were mounted onto glass slides using a Zeiss Axioscope inverted fluorescence microscope (Zeiss, Oberkochen, Germany).
Western blotting. Cells were lysed in $1 \times$ RIPA buffer $(20 \mathrm{mM}$ TRIS-HCl $(\mathrm{pH}$ 7.5), $150 \mathrm{mM} \mathrm{NaCl}, 1 \mathrm{mM}$ EDTA, $1 \mathrm{mM}$ EGTA, 1\% (v/v) IGEPAL, 1\% (w/v) deoxycholate, $250 \mathrm{mM}$ sodium pyrophosphate and Complete-mini protease inhibitor cocktail (Roche, Basel, Switzerland) and incubated on ice for $15 \mathrm{~min}$. Lysates were spun at 13000 r.p.m. for $5 \mathrm{~min}$ to pellet cell debris. The supernatant was transferred to a clean tube and assayed for protein using the BCA assay kit according to the manufacturer's instructions (Pierce). Twenty micrograms total protein was run on denaturing PAGE gels in protein running buffer $(25 \mathrm{mM}$ TRIS-HCl, $192 \mathrm{mM}$ glycine, $0.1 \%(\mathrm{w} / \mathrm{v})$ sodium dodecyl sulphate) and wet-transferred in transfer buffer $(25 \mathrm{mM}$ TRIS-HCl, $192 \mathrm{mM}$ glycine, $0.1 \%$ (w/v) sodium dodecyl sulphate containing $20 \%$ $(\mathrm{v} / \mathrm{v})$ methanol) to Hybond-C nitrocellulose membrane (GE Healthcare, Little Chalfont, UK). Membranes were blocked for $60 \mathrm{~min}$ in $5 \%$ (w/v) non-fat dry milk in PBS for $1 \mathrm{~h}$ at room temperature before being incubated with primary antibody 
(Cell Signalling Danvers, MA, USA) overnight at 1/1000 dilution in 5\% (w/v) non-fat dry milk in PBS at $4{ }^{\circ} \mathrm{C}$. The following day they were washed three times in PBS containing $0.1 \%(\mathrm{v} / \mathrm{v})$ Tween-20. Horseradish-peroxidase conjugated secondary antibodies (DAKO, Ely, UK) were used at 1/5000 dilution in $5 \%$ (w/v) non-fat dry milk for $1 \mathrm{~h}$ at room temperature and then washed three times in PBS containing $0.1 \%$ (v/v) Tween-20. Bands were visualised using enhanced chemiluminescence (GE Healthcare, UK).

Statistical analysis. Statistical analyses were performed using GraphPad Prism software 4.0c (GraphPad Software, La Jolla, CA, USA). Normally distributed data were analysed by parametric $t$-test and non-normally distributed data by nonparametric Mann-Whitney U-test. For multiple means comparisons, one-way analysis of variance (ANOVA) followed by Tukey post hoc test was used to determine statistical significance.

Study approval. All animal studies were approved by the University College London Biological Services Ethical Review Committee and licensed under the UK Home Office regulations and the Guidance for the Operation of Animals (Scientific Procedures) Act 1986 (Home Office, London, UK).

\section{Conflict of Interest}

The authors declare no conflict of interest.

Acknowledgements. LB is supported by the Grand Challenge PhD Studentship Programme, UCL and Lupus UK. YI is supported by the National Institute for Health Research University College London Hospitals Biomedical Research Centre and Arthritis Research UK Grant 20164. CP and VRN are supported by Arthritis Research UK Programme Grant 19423. TM is supported by an MRC CASE studentship.

1. Miyakis S, Lockshin MD, Atsumi T, Branch DW, Brey RL, Cervera R et al. International consensus statement on an update of the classification criteria for definite antiphospholipid syndrome (APS). J Thromb Haemost 2006; 4: 295-306.

2. Bouma B, de Groot PG, van den Elsen JM, Ravelli RB, Schouten A, Simmelink MJ et al. Adhesion mechanism of human beta(2)-glycoprotein I to phospholipids based on its crystal structure. EMBO J 1999; 18: 5166-5174.

3. Schwarzenbacher R, Zeth K, Diederichs K, Gries A, Kostner GM, Laggner P et al. Crysta structure of human beta2-glycoprotein I: implications for phospholipid binding and the antiphospholipid syndrome. EMBO J 1999; 18: 6228-6239.

4. Hunt J, Krilis S. The fitth domain of beta 2-glycoprotein I contains a phospholipid binding site (Cys281-Cys288) and a region recognized by anticardiolipin antibodies. J Immunol 1994; 152: $653-659$.

5. Iverson GM, Victoria EJ, Marquis DM. Anti- $\beta 2$ glycoprotein I ( $\beta 2 \mathrm{GPI})$ autoantibodies recognize an epitope on the first domain of $\beta 2$ GPI. Proc Natl Acad Sci USA 1998; 95: 15542-15546.

6. Reddel SW, Wang YX, Sheng YH, Krilis SA. Epitope studies with anti- $\beta 2$-glycoprotein I antibodies from autoantibody and immunized sources. I Autoimmunity 2000; 15 91-96.

7. Pericleous C, Ruiz-Limón P, Romay-Penabad Z, Marín AC, Garza-Garcia A, Murfitt L et al. Proof-of-concept study demonstrating the pathogenicity of affinity-purified IgG antibodies directed to domain I of $\beta 2$-glycoprotein I in a mouse model of anti-phospholipid antibodyinduced thrombosis. Rheumatology 2015; 54: 722-727.

8. Ioannou Y, Romay-Penabad Z, Pericleous C, Giles I, Papalardo E, Vargas G et al. In vivo inhibition of antiphospholipid antibody-induced pathogenicity utilizing the antigenic target peptide domain I of $\beta 2$-glycoprotein I: proof of concept. J Thromb Haemost 2009; 7: 833-842.

9. Belizna CC, Richard V, Primard E, Kerleau JM, Cailleux N, Louvel JP et al. Early atheroma in primary and secondary antiphospholipid syndrome: an intrinsic finding. Semin Arthritis Rheum 2008; 37: 373-380.

10. Andreoli L, Chighizola CB, Banzato A, Pons-Estel GJ, Ramire de Jesus G, Erkan D. Estimated frequency of antiphospholipid antibodies in patients with pregnancy morbidity, stroke, myocardial infarction, and deep vein thrombosis: a critical review of the literature. Arthritis Care Res 2013; 65: 1869-1873.

11. Fleming SD, Monestier M, Tsokos GC. Accelerated ischemia/reperfusion-induced injury in autoimmunity-prone mice. J Immunol 2004; 173: 4230-4235.

12. Love PE, Santoro SA. Antiphospholipid antibodies: anticardiolipin and the lupus anticoagulant in systemic lupus erythematosus (SLE) and in non-SLE disorders prevalence and clinical significance. Ann Intern Med 1990; 112: 682-698.
13. Fleming SD, Egan RP, Chai C, Girardi G, Holers VM, Salmon J et al. Anti-phospholipid antibodies restore mesenteric ischemia/reperfusion-induced injury in complement receptor 2/complement receptor 1-deficient mice. J Immunol 2004; 173: 7055-7061.

14. Sinicato NA, Cardoso PAdS, Appenzeller S. Risk factors in cardiovascular disease in systemic lupus erythematosus. Curr Cardiol Rev 2013; 9: 15-19.

15. Yaoita H, Ogawa K, Maehara K, Maruyama Y. Attenuation of ischemia/reperfusion injury in rats by a caspase inhibitor. Circulation 1998; 97: 276-281.

16. Martin JL, Avkiran M, Quinlan RA, Cohen P, Marber MS. Ant-ischemic effects of SB203580 are mediated through the inhibition of $\mathrm{p} 38 \alpha$ mitogen-activated protein kinase: evidence from ectopic expression of an inhibition-resistant kinase. Circ Res 2001; 89: 750-752.

17. Nagarkatti DS, Sha" afi RI. Role of p38 MAP kinase in myocardial stress. J Mol Cell Cardiol 1998; 30: 1651-1664.

18. Zhang $M$, Chen $L$. Status of cytokines in ischemia reperfusion induced heart injury. Cardiovasc Hematol Disord Drug Targets 2008; 8: 161-172.

19. Giles IP, Isenberg DA, Latchman DS, Rahman A. How do antiphospholipid antibodies bind 32-glycoprotein I? Arthritis Rheum 2003; 48: 2111-2121.

20. Vega-Ostertag M, Casper K, Swerlick R, Ferrara D, Harris EN, Pierangeli SS. Involvement of p38 MAPK in the up-regulation of tissue factor on endothelial cells by antiphospholipid antibodies. Arthritis Rheum 2005; 52: 1545-1554.

21. López-Pedrera C, Buendía $P$, José Cuadrado $M$, Siendones $E$, Angeles Aguirre M, Barbarroja $\mathrm{N}$ et al. Antiphospholipid antibodies from patients with the antiphospholipid syndrome induce monocyte tissue factor expression through the simultaneous activation of $\mathrm{NF}-\mathrm{kB} /$ Rel proteins via the $\mathrm{p} 38$ mitogen-activated protein kinase pathway, and of the MEK-1/ ERK pathway. Arthritis Rheum 2006; 54: 301-311.

22. Bohgaki M, Atsumi T, Yamashita Y, Yasuda S, Sakai Y, Furusaki A et al. The p38 mitogenactivated protein kinase (MAPK) pathway mediates induction of the tissue factor gene in

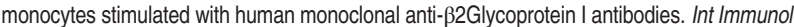
2004; 16: 1633-1641.

23. Lambrianides A, Carroll CJ, Pierangeli SS, Pericleous C, Branch W, Rice $\mathrm{J}$ et al. Effects of polyclonal $\operatorname{lgG}$ derived from patients with different clinical types of the antiphospholipid syndrome on monocyte signaling pathways. J Immunol 2010; 184: $6622-6628$.

24. Nojima J, Masuda $Y$, Iwatani $Y$, Kuratsune $H$, Watanabe $Y$, Suehisa E et al. Arteriosclerosis obliterans associated with anti-cardiolipin antibody/ $\beta 2$-glycoprotein I antibodies as a strong risk factor for ischaemic heart disease in patients with systemic lupus erythematosus. Rheumatology 2008; 47: 684-689.

25. Fisk M, Gajendragadkar PR, Maki-Petaja KM, Wilkinson IB, Cheriyan J. Therapeutic potential of p38 MAP kinase inhibition in the management of cardiovascular disease. Am J Cardiovasc Drugs 2014; 14: 155-165.

26. McNeil HP, Simpson RJ, Chesterman CN, Krilis SA. Anti-phospholipid antibodies are directed against a complex antigen that includes a lipid-binding inhibitor of coagulation: beta 2-glycoprotein I (apolipoprotein H). Proc Natl Acad Sci USA 1990; 87: $4120-4124$.

27. Galli M, Barbui T, Comfurius P, Maassen C, Hemker HC, Zwaal RFA et al. Anticardiolipin antibodies (ACA) directed not to cardiolipin but to a plasma protein cofactor. Lancet 1990; 335: 1544-1547.

28. de Laat HB, Derksen RHWM, Urbanus RT, Roest M, de Groot PG. $\beta 2$-glycoprotein I-dependent lupus anticoagulant highly correlates with thrombosis in the antiphospholipid syndrome. Blood 2004; 104: 3598-3602.

29. Matsuura E, Igarashi Y, Yasuda T, Triplett DA, Koike T. Anticardiolipin antibodies recognize beta 2-glycoprotein I structure altered by interacting with an oxygen modified solid phase surface. J Exp Med 1994; 179: 457-462.

30. Lazzerini PE, Capecchi PL, Laghi-Pasini F. Anti-Ro/SSA antibodies and cardiac arrhythmias in the adult: facts and hypotheses. Scand J Immunol 2010; 72: 213-222.

31. Ioannou Y, Pericleous C, Giles I, Latchman DS, Isenberg DA, Rahman A. Binding of antiphospholipid antibodies to discontinuous epitopes on domain I of human $\beta(2)$-glycoprotein I: mutation studies including residues R39 to R43. Arthritis Rheum 2007; 56: 280-290.

32. Ioannou Y, Giles I, Lambrianides A, Richardson C, Pearl L, Latchman D et al. A novel expression system of domain I of human beta2 glycoprotein I in Escherichia coli. BMC Biotechnol 2006; 6: 1-11

33. Raschi E, Testoni C, Bosisio D, Borghi MO, Koike T, Mantovani A et al. Role of the MyD88 transduction signaling pathway in endothelial activation by antiphospholipid antibodies. Blood 2003; 101: 3495-3500.

34. Ma K, Simantov R, Zhang J-C, Silverstein R, Hajjar KA, McCrae KR. High affinity binding of $\beta 2-$ glycoprotein I to human endothelial cells is mediated by Annexin II. J Biol Chem 2000; 275: 15541-15548.

35. Reed JH, Giannakopoulos B, Jackson MW, Krilis SA, Gordon TP. Ro 60 functions as a receptor for $\beta 2$-glycoprotein I on apoptotic cells. Arthritis Rheum 2009; 60: 860-869.

36. Faure E, Thomas L, Xu H, Medvedev AE, Equils O, Arditi M. Bacterial lipopolysaccharide and IFN- $\gamma$ induce Toll-like receptor 2 and Toll-like receptor 4 expression in human endothelial cells: role of NF-кB activation. J Immunol 2001; 166: 2018-2024.

37. Hua F, Ha T, Ma J, Li Y, Kelley J, Gao X et al. Protection against myocardial ischemia/ reperfusion injury in TLR4-deficient mice is mediated through a phosphoinositide 3-kinasedependent mechanism. J Immunol 2007; 178: 7317-7324.

38. Zhao P, Wang J, He L, Ma H, Zhang X, Zhu X et al. Deficiency in TLR4 signal transduction ameliorates cardiac injury and cardiomyocyte contractile dysfunction during ischemia. J Cell Mol Med 2009; 13: 1513-1525. 
39. Miyakis S, Lockshin MD, Atsumi T, Branch DW, Brey RL, Cervera R et al. International consensus statement on an update of the classification criteria for definite antiphospholipid syndrome (APS). J Thromb Haemost 2006; 4: 295-306.

40. Tan EM, Cohen AS, Fries JF, Masi AT, McShane DJ, Rothfield NF et al. The 1982 revised criteria for the classification of systemic lupus erythematosus. Arthritis Rheum 1982; 25: 1271-1277.

41. Pericleous C, Clarke LA, Brogan PA, Latchman DS, Isenberg DA, loannou $Y$ et al. Endothelial microparticle release is stimulated in vitro by purified IgG from patients with the antiphospholipid syndrome. Thromb Haemost 2013; 109: 72-78.

42. Pericleous C, Miles J, Esposito D, Garza-Garcia A, Driscoll PC, Lambrianides A et al. Evaluating the conformation of recombinant domain I of $\beta 2$-glycoprotein I and its interaction with human monoclonal antibodies. Mol Immunol 2011; 49: 56-63.

43. Bourke L KR, Latchman D, Stephanou A, McCormick J. Signal transducer and activator of transcription-1 localizes to the mitochondria and modulates mitophagy. Jak-Stat 2013; 2: e25666.
Cell Death and Disease is an open-access journal published by Nature Publishing Group. This work is licensed under a Creative Commons Attribution 4.0 International License. The images or other third party material in this article are included in the article's Creative Commons license, unless indicated otherwise in the credit line; if the material is not included under the Creative Commons license, users will need to obtain permission from the license holder to reproduce the material. To view a copy of this license, visit http://creativecommons.org/licenses/by/4.0/

(C) The Author(s) 2017

Supplementary Information accompanies this paper on Cell Death and Disease website (http://www.nature.com/cddis) 